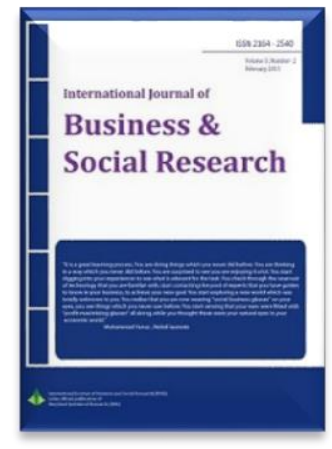

\title{
Redesigning Scenarios and Defining Business Opportunities
}

\author{
Hakan BÜTÜNER ${ }^{1}$
}

\begin{abstract}
The purpose of this paper is to help businesses to define their business opportunities that are most attractive and feasible for them by using newly developed practical techniques. It is intended to find the factors that would affect and change the outlook mostly in the current status and anticipated future, based on the results obtained from environmental analysis. In short, using the trends to be revealed by the environmental analysis, it is possible to anticipate how the field of business in which we operate or plan to enter will evolve in the future. The status is reviewed according to the assumptions and the results to be obtained are evaluated. Thus, assumptions are grouped under various scenarios, their potential impacts on the industry are identified, and the potential status in the industry is defined. In conclusion, taking into consideration the characteristics of the business that offer competitive advantages, the potential opportunities for the business in the industry are identified. Another intention here is to provide strategic planners an easily understandable and applicable comprehensive procedure by assembling the disconnected and disorderly ideas, processes and techniques.
\end{abstract}

Keywords: Business opportunities, developing scenarios, opportunities, scenarios, strategy.

JEL Codes: M100, M130, M160.

Available Online: 20-04-2016.

This is an open access article under Creative Commons Attribution 4.0 License, 2016.

\subsection{INTRODUCTION}

The main purpose of this paper is to help a business to define its business opportunities by developing scenarios for the future of its existing industry and matching these positive scenarios with the competitive position of the business.

Basically, I felt the need for a comprehensive procedure of defining business opportunities. I wanted the procedure to be easy to understand and straight forward and to be universally applicable to any type of business. Another intention here is to assemble the disconnected and disorderly ideas,

\footnotetext{
${ }^{1}$ Turgut Özal University, Business Management, IMECO - Industrial Management \& Engineering Co.

E-mail: hakan.butuner@imeco-tr.com
} 
processes, and techniques (written on business opportunities) under the same roof, in order to develop a systematic procedure that is easily understandable and applicable. Moreover, as it could be a fond phrase to say that there is an exact approach or systematic thinking on this issue, my intention was to bring in a new perspective to the reader and more significantly to provide a different benefit by the application of this systematic procedure.

Where analysis tools are explained this is most frequently done conceptually rather than showing how to use the tools for defining business opportunities. This paper provides a complete set of practical techniques/tools. Where appropriate, I have refined these tools (from their original sources) to make them more user-friendly and effective.

The content of this paper (which is summarized as below) is composed as a result of the conclusions obtained from different application environments of the issue in subject and by the composition of the cause and effect relations of these.

It is intended to find the factors that would affect and change the outlook mostly in the current status and anticipated future, based on the results obtained from environmental analysis. The external variables that are most sensitive and that would affect the results most if changed are identified and value impact matrix is created. In short, using the trends to be revealed by the environmental analysis, it is possible to anticipate how the field of business in which we operate or plan to enter will evolve in the future. (It must be remembered that an external variable with ignorable impact in current status may have an unexpectedly increased influence in the future depending on other factors, which could lead to changes in the results of all analyses conducted.) For instance, information may be obtained about the way how customer expectations will evolve and develop in the future.

Assumptions are made on these variables, for instance through brainstorming approach. The status is reviewed according to the assumptions and the results to be obtained are evaluated. It is important that this is continuously repeated taking into consideration evolving conditions and innovations. Thus, assumptions are grouped under various scenarios, their potential impacts on the industry are identified, and the potential status in the industry is defined. Scenarios view the future, focus on discontinuity and change, and explore the impact of the change on key players and how they respond to the environment.

In conclusion, taking into consideration the characteristics of the business that offer competitive advantages, the potential opportunities for the business in the industry are identified. Figure 1 shows the procedure of identifying opportunities (Butuner, 2015).

Throughtout this paper, for the sake of understanding well, in addition to several examples, an example case (Butuner, 2016) will also be introduced to support the suggested approach:

"Abler by Robomedika will create an innovative brand and establish a company which designs and produces innovative medical machinery. The company will touch patient's life and make life easier for handicapped people. The brand is Abler that will be the innovative and new generation wheel chair and will be designed by Robomedika engineers." 
Figure 1: Procedure of identifying opportunities

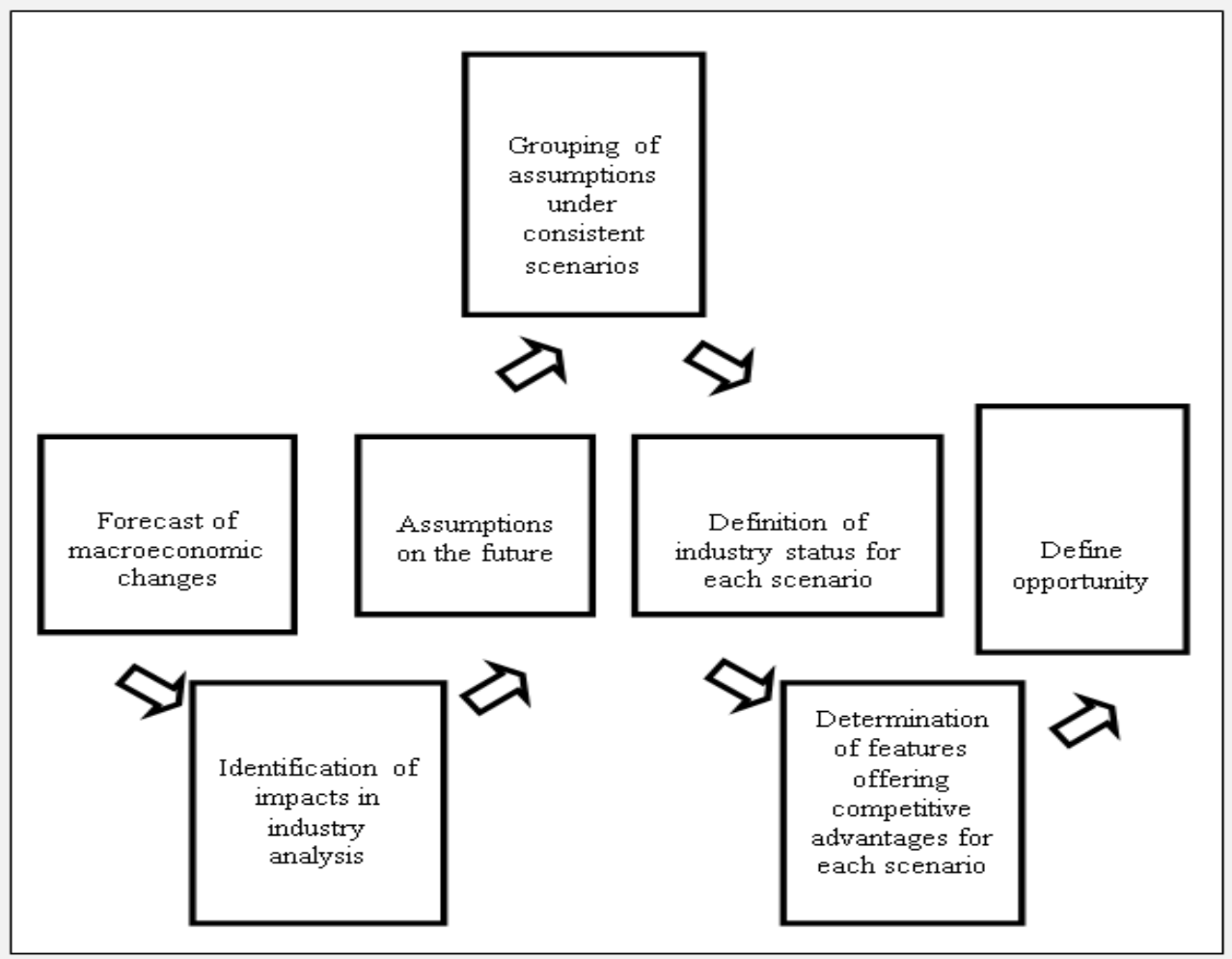

Assumptions imply the external factors that are not under the direct control of the business preparing the scenarios but that can affect the progress and success of its strategic plan. After reviewing socio cultural factors, technological factors, political environmental, legal conditions, macro-economic factors and variables originating from international system in the environmental analysis (Wheelen et al., 2001), the tendencies of related parties such as competitors, customers and suppliers (Porter, 1998) must reflect onto the development of scenarios as assumptions.

First, key external variables are identified. Assumptions are made for the values of quantitative and qualitative variables (through brainstorming or statistical models.) Brain storming and/or statistical models are popular estimation techniques:

- Brain storming is a non-numerical estimation technique (Fligor, 1990). While conducting scenario analysis, instruments like participatory meetings bringing together various groups concerning the business are used. For the efforts to be made in this scope, it is possible to outsource specialized services, such as the use of facilitators (moderators) who will neutrally facilitate participatory meetings.

- Statistical models are numerical techniques including relations and other econometric models. However it is based on historical data, and error margin increases as the structure of relations changes in time.

Make your assumptions as specific as possible - set parameters (e.g. is project $X$ will be running smoothly for users by December $\mathrm{Y}$ ). The most significant estimation errors arise from; wrong assumptions, adaptations of reflecting today's trends to future.

"Suppose by analyzing the environmental factors of the example case - Abler, the following assumptions are generated (Table 1): 
Table 1: Assumptions on future - Example Case

1. Turkish government increases the budget for social security and health care system.

2. Economic growth of Turkey increases higher than expected.

3. Turkish government provides higher incentives for high-tech startups.

4. Caucasian and Middle Eastern markets for health support equipment will grow.

5. Euro/TL parity increases so high that Turkish companies have price advantages.

6. There will be strict restrictions for low quality health care equipment which may reduce Chinese competitive power.

7. Transportation costs from China to Turkey may decrease due to the higher return loads from Turkey to China.

8. Russia gives importance to health care equipment market.

9. New developments in medical science allow handicapped patients get well.

Forecasting the Quantitative Impacts of Macro-Economic Variables

The value of utilizing such a multidimensional analysis of the future environment lies in the fact that (Butuner, 2015):

- It makes explicit all the assumptions on which planning should be based.

- It integrates the social factors and the business factors into the planning framework.

- It identifies the spectrum of probable future constraints and opportunities for business performance.

- It provides an opportunity for determining needed business responses to changing conditions.

Essentially the forecasting is done in four steps (Aaker et al., 2000):

1. Select critical indicators:

- Identify the industry's key indicators (trends).

- Undertake literature search to identify potential future events impacting the key trends.

2. Establish past behavior for each indicator:

- Establish the historical performance for each indicator.

- Use data for the Trend Impact Analysis.

- Analyze reasons for past behavior of each trend:

- Demographic and social.

- Economic.

- Political and legislative.

- Technological.

3. Verify potential future events:

- Interrogate Delphi panel:

- Evaluate past trends.

- Assess the potential impact of future events.

- Assess the probability of future events.

- Forecast future values.

- Specify and document assumptions.

- Specify and document rationale for projected values.

4. Forecast each indicator:

- Operate the Trend Impact and Cross Impact Analysis to establish the range of future values.

- Analyze forecast results.

An example of using regression model for forecasting the quantitative impacts of macro-economic variables (Butuner, 2015):

"As far as the dynamics of construction industry and construction materials sub-sector are concerned, the primary factors affecting supply and demand growth in the industry are shown in Table 2. 
Table 2: Primary factors in construction industry

1. GNP growth rate

2. Growth in number of households

3. Population growth rate

4. Growth in number of licensed buildings

5. Increase in unit $\mathrm{m} 2$ price of buildings

Therefore, the following example involves the projection of these five rates, taking as a basis the past 20 years (Table 3). Forecasts were obtained to be taken as the denominator of each rate. These reveal the forecasts of trends for future rates as well as the number of licensed apartments that forms the numerator in each rate. Often an arithmetic mean of these rates may be used.

$$
\begin{aligned}
& y=-411.7+0.1117 x_{1}+1.526 x_{2}+0.1236 x_{3}+1.8409 x_{4}+0.3820 x_{5} \\
& x_{1}: \text { Growth of GNP per capita } \\
& x_{2}: \text { Growth in number of households } \\
& x_{3}: \text { Population growth } \\
& x_{4}: \text { Growth in number of licensed buildings } \\
& x_{5}: \text { Increase in unit } m^{2} \text { building prices" }
\end{aligned}
$$

\begin{tabular}{|c|c|c|c|c|c|c|}
\hline \multicolumn{7}{|c|}{ Table 3: Projection of five primary factors in construction industry } \\
\hline Years & $\begin{array}{r}\text { Licensed No. of } \\
\text { Flats Growth } \\
(000)(y)\end{array}$ & $\begin{array}{r}\text { GNP per Capita } \\
\text { Increase (0oo) } \\
(\mathrm{xl})\end{array}$ & $\begin{array}{r}\text { Growth } \\
\text { Households } \\
(\times 2)\end{array}$ & $\begin{array}{r}\text { Pop. } \\
\text { Growth } \\
\text { Rate }(\times 3)\end{array}$ & $\begin{array}{r}\text { Licensed } \\
\text { Build. Growth } \\
(\mathrm{x} 4)\end{array}$ & $\begin{array}{r}\text { Building m2 } \\
\text { Price Increase } \\
(\times 5)\end{array}$ \\
\hline 1977 & 216 & 11 & 295 & 853 & 25 & 6 \\
\hline 1978 & 237 & -11 & 307 & 872 & 26 & 44 \\
\hline 1979 & 252 & -31 & 323 & 890 & 31 & 33 \\
\hline 1980 & 204 & -57 & 330 & 908 & 32 & -49 \\
\hline 1981 & 144 & 26 & 229 & 1102 & 27 & -19 \\
\hline 1982 & 160 & 6 & 235 & 1148 & 49 & -7 \\
\hline 1983 & 169 & 20 & 242 & 1176 & 37 & -3 \\
\hline 1984 & 189 & 53 & 247 & 1206 & 38 & -6 \\
\hline 1985 & 259 & 22 & 255 & 1236 & 77 & 13 \\
\hline 1986 & 393 & 56 & 276 & 1127 & 143 & 17 \\
\hline 1987 & 498 & 99 & 283 & 1128 & 160 & -1 \\
\hline 1988 & 474 & -10 & 292 & 1154 & 168 & 7 \\
\hline 1989 & 413 & -8 & 300 & 1178 & 132 & 19 \\
\hline 1990 & 381 & 96 & 308 & 1205 & 71 & 30 \\
\hline 1991 & 393 & -24 & 317 & 1228 & 77 & 21 \\
\hline 1992 & 473 & 66 & 326 & 1258 & 123 & 7 \\
\hline 1993 & 548 & 95 & 335 & 1285 & 136 & 5 \\
\hline 1994 & 524 & -128 & 345 & 1314 & 132 & -46 \\
\hline 1995 & 508 & 92 & 355 & 1343 & 99 & 15 \\
\hline 1996 & 446 & 91 & 364 & 1372 & 94 & -1 \\
\hline
\end{tabular}

\subsection{GROUPING OF ASSUMPTIONS AS SCENARIOS}

As a result of studies and researches to be conducted for assumptions, the business will group the scenarios for its own industry, and summarize them in a table.

Against the developments that may occur in the environment beyond the control of the business, the business will prepare alternative scenarios for the future. Based on the assumption that any unexpected development may occur in the future, the business must always be prepared for such cases and constantly follow up the developments. As a natural consequence of this approach, scenarios need to be based on a flexible structure and revised continuously according to trends and developments.

The purpose of scenario analysis is to make decisions for the future based on limited number of scenarios produced (Wheelen et al., 2001). Various views and expectations will arise while developing 
scenarios. The scenarios produced must encompass these views to the extent possible. Points to consider while developing scenarios:

- What will be the boundaries of the industry 5 years later? What are the current boundaries and the value added chains linked to the industry which you consider joining?

- Which actors may significantly affect the development of scenarios?

- Who, and to what extent, will be affected from the developments in the industry?

- What are the factors giving direction to the future of the industry? What are the critical unknown factors, rather than the factors possible to forecast?

- What is the most important change that will occur in the sector's structure and balance of powers?

- While scenarios are written in detail, they must be freed from internal inconsistencies.

- Detailed scenarios should not describe the situation 5 years later, but rather tell about the developments that would take us there during 5 years.

\subsection{1}

\section{GROUPING OF ASSUMPTIONS}

Position the key assumptions which underpin an issue. Write the assumption in shorthand on a yellow post-it and position relative to others on the grid. Test out relative and absolute positioning.

"Figure 2 can be used as a certainty and importance grid for positioning the assumptions (shown in Table 1 for Abler case) which are derived from environmental analysis."

\subsection{2}

\section{GENERATING SCENARIOS}

Generate scenarios by testing out judgments and identifying interdependencies as is shown in Figure 3 (Butuner, 2015):

1. Prepare a list of basic assumptions.

2. Rank the assumptions according to probability of actualization and importance using Figure 2.

3. Convert the classification of each assumption into quantitative values $(A=4, E=3 \ldots)$; multiply the values, and select the two or three assumptions with highest value.

4. Use the selected assumptions individually or as a group to diversify the basic scenario.

"Accordingly, in Abler case, the list of events that have rates above 3 (shown in Figure 3) are used for developing alternative scenario definitions."

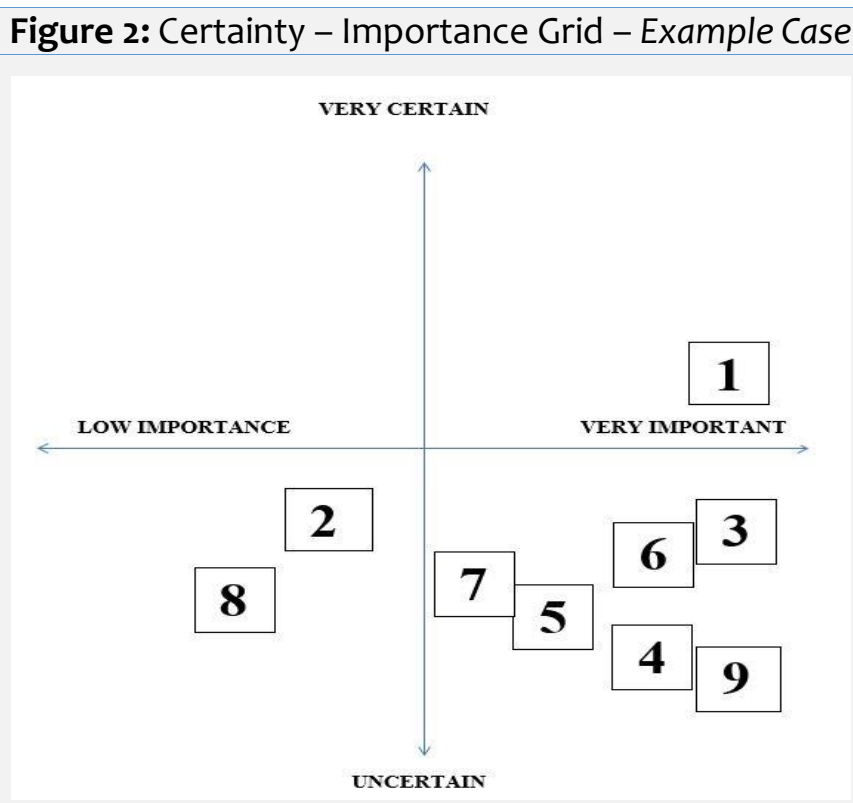


Positive Scenarios - Abler Case:

"Based on event 1, governments worldwide increase their budget for healthcare and social security systems which increase the size of medical market. In addition to this progress, economic growth also improves the sales and profitability.

Based on event 3, Turkish government gives incentives to local startups in medical field.

Based on event 6, the restrictions on low quality Chinese products, Turkish brands may have best price/performance ratios which may help them both in local and global competition."

Figure 3: Generating scenarios - Example case

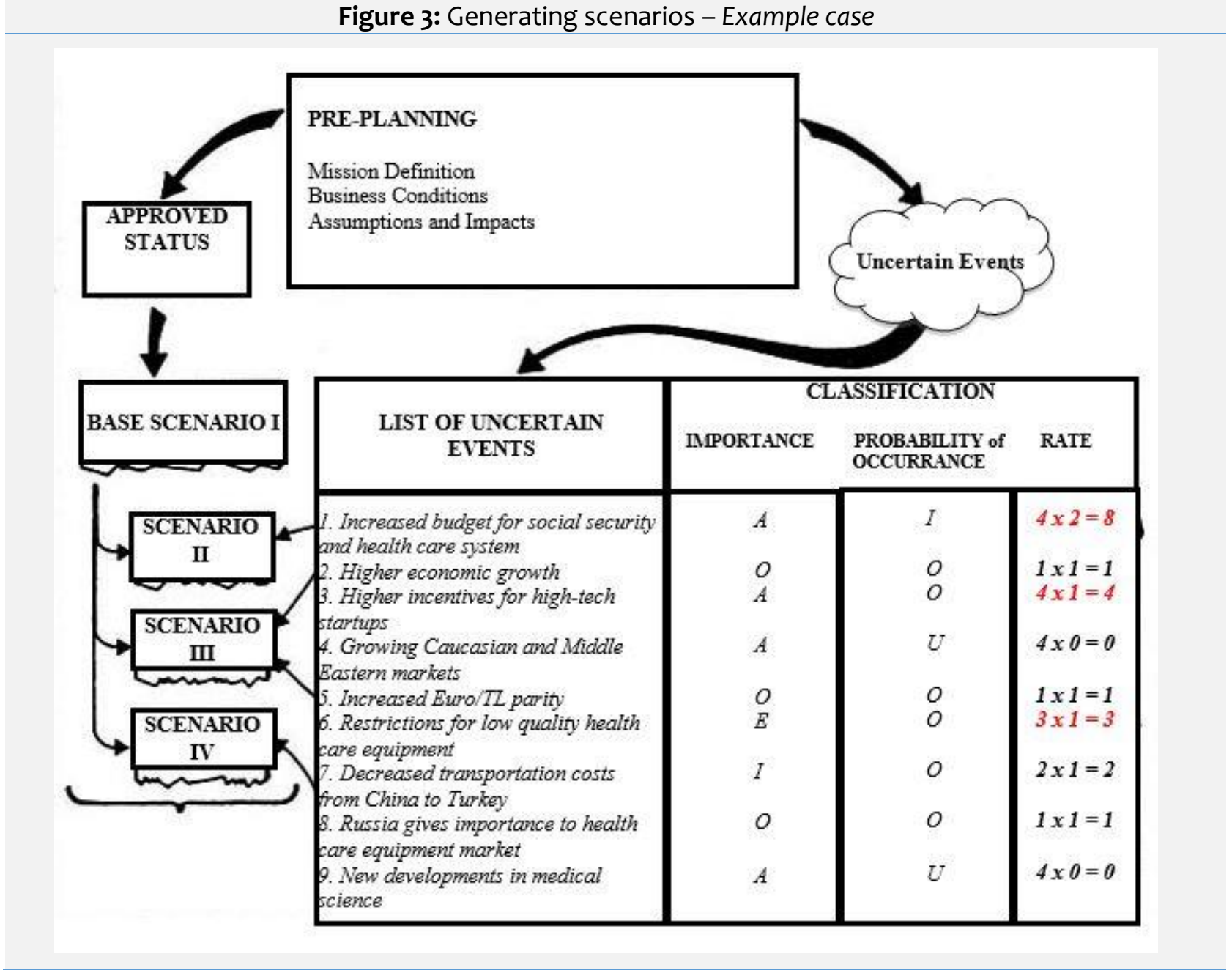

\subsection{DEFINING BUSINESS OPPORTUNITIES}

The opportunities that may be offered and posed for the business under the positive scenarios to come out from scenario analysis must be identified. Moreover, determining the strengths of the company compared to its competitors will be able to carry the analysis to a satisfactory result (Hitt et al., 2005). In short, competitive advantages of the business need to be matched with the potential positive (attractive) scenarios in the industry. The competitive advantages when matched with the result of scenarios, provides the critical foundation for opportunities formulation.

Opportunities, by definition, arise in cases where the unresolved problems and unsatisfied expectations and needs are identified for use of products in the market, and if solutions can be produced for these.

An opportunity, then, is the possibility to do things both differently and better than how they are being done at the moment (Wickham, 2004). In economic terms, differently might take the form of offering a new product or of organizing the business in a different way. Better means the product offers a utility in terms of an ability to satisfy human needs that existing products do not. 


\subsection{MATCHING POSITIVE SCENARIOS WITH COMPETITIVE POSITIONS}

By testing out total market attractiveness of each positive scenario, you would be able to screen out investment opportunities even before considering what kind of competitive advantages you might be able to attain. The attractiveness is the net benefits less the costs (not just the benefits.)

Drivers of growth is used for assessing the market attractiveness of a particular positive scenario. This is accomplished through vector analysis (Ansoff, 1970) which is a way of mapping the impact of forces for growth in an industry.

Besides market attractiveness of a scenario, to position a business effectively on the GE grid (Rasiel, 1999) you also need to take some view of its competitive position (Montgomery et al., 1991) w.r.t. the particular scenario. The following ten key criteria will usually suffice:

- Brand, image and reputation

- Simplicity of product/market focus, or alternatively a relevant and broad offering

- Relative market (or niche) share

- Product and service performance

- Distribution channels

- Cost base

- Responsiveness (but this doesn't mean reactiveness)

- Technical and non-technical competencies

- Financial strength

- Management skills

The above factors can be scored as strong, average or weak. Also, the relative importance of the factors can be assessed by weighting some factors as being more important than others.

"Accordingly, it is assumed that by analyzing the internal factors of Abler and comparing its strengths with main competitors, product performances, cost base, responsiveness, technical and non-technical competencies and management skills can help Abler taking a competitive position w.r.t the first positive scenario (shown in Table 4)."

Table 4: Competitive position w.r.t. a Particular scenario - Example case

$\begin{array}{lrrr}\begin{array}{l}\text { Brand, Image and Reputation } \\ \text { Simplicity of Product/Market Focus }\end{array} & \text { WEAK } & \text { MEDIUM } & \text { STRONG } \\ \begin{array}{l}\text { Relative Market (or Niche) Share } \\ \text { Product and Service Performances }\end{array} & + & + & \\ \begin{array}{l}\text { Distribution Channels } \\ \text { Cost Base }\end{array} & + & + \\ \begin{array}{l}\text { Responsiveness } \\ \text { Technical and Non-technical }\end{array} & & + \\ \begin{array}{l}\text { Competencies } \\ \text { Financial Strength }\end{array} & & + \\ \text { Management Skills } & & + \\ & + & +\end{array}$

\subsection{BUSINESS OPPORTUNITIES}

Figure 4 shows the GE (Rasiel, 1999) grid that enables you to

- Position a business, having determined market attractiveness of a scenario and competitive position of a business w.r.t the particular scenario

- Evaluate business opportunities

- Reposition a business (from right to left on the GE grid, or even (by shifting the business' market focus) diagonally north-west) 
- Challenge the adequacy of investment to achieve such a repositioning (both long-term investment and revenue costs with longer term benefits)

- Compare your positioning with other key competitors operating in the same or different market segments

Figure 4: Business opportunities

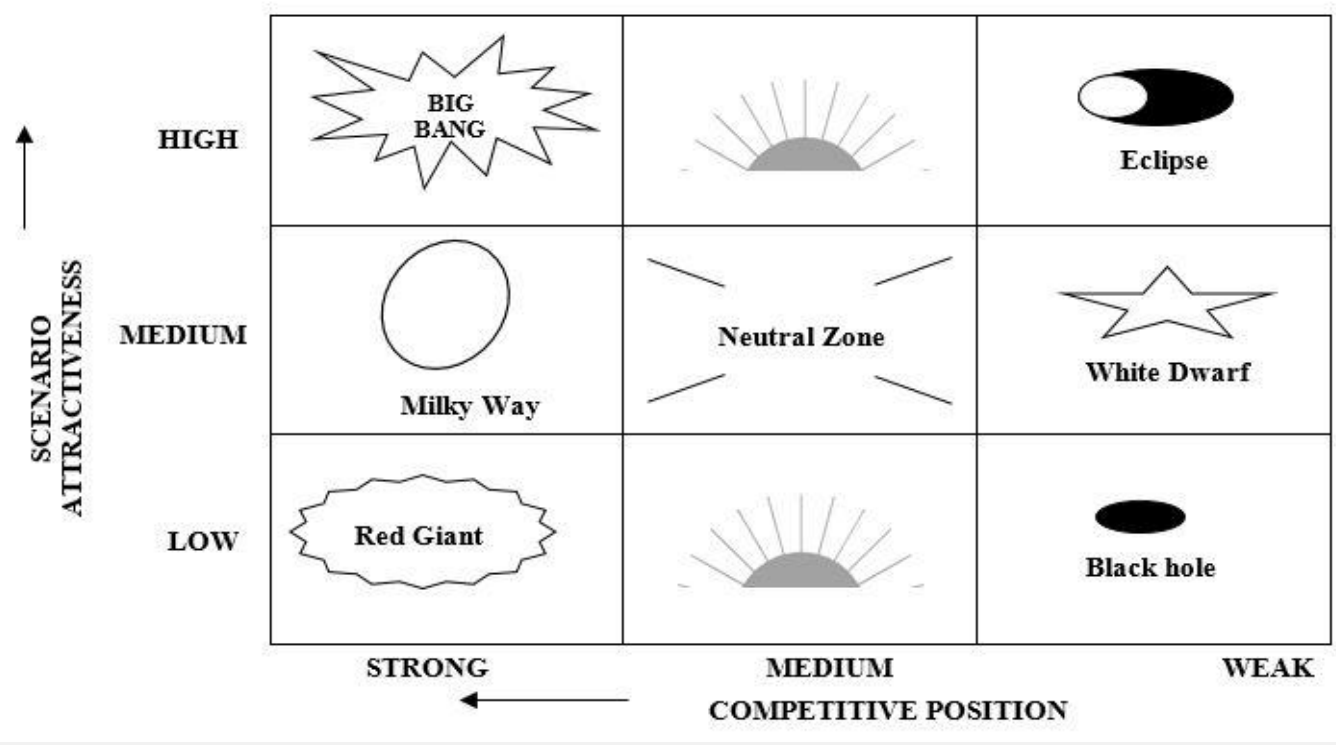

"Accordingly, first positive scenario can be considered as a Big Bang for Abler as market attractiveness of this scenario is quite high and as Abler has high competitive position w.r.t this scenario, Abler can turn this into an opportunity for itself.

High profitability and low number of players point out the attractiveness of the medical market, but high $R \& D$ expenses and wide distribution channels require a great amount of investment capital. Accordingly, the market is quite attractive for financially powered players but quite risky for startups.

However, on one side there are high-tech global giants and on the other side there are low cost Chinese companies, which means it is not easy to compete with any one of these sides and therefore entry barrier should be considered seriously."

\subsection{SCREENING AND SELECTING OPPORTUNITIES}

Not all opportunities are equally valuable. A business with limited resources cannot pursue every opportunity with which it is faced. It must select those opportunities which are going to be the most rewarding. The key decisions in screening and selecting opportunities relate to the size of the opportunity, the investment necessary to exploit it, the rewards that will be gained and the risks likely to be encountered. Specifically, the decision on selecting opportunities, illustrated in Figure 5, should be based on the answers to the following questions (Butuner, 2015):

- Market attractiveness: is the market (or segment) inherently attractive (consider key growth drivers and brakes?)

- Competitive advantage: are we likely to have (and be able to sustain) a competitive position?

- Financial attractiveness: are we likely to make enough money out of it?

- Implementation capability: do we have the capability, resources and commitment to implement it effectively? 
Figure 5: Selection of opportunities - Prioritization

\begin{tabular}{|l|l|l|l|l|}
\cline { 2 - 5 } \multicolumn{1}{c|}{} & \multicolumn{3}{|c|}{ FINANCIAL ATTRACTIVENESS } & Loderate \\
\hline $\begin{array}{l}\text { IMPLEMENTATION } \\
\text { CAPABILITY }\end{array}$ & Very High & High & Low \\
Capable & & & & \\
\hline $\begin{array}{l}\text { E-Especially } \\
\text { Capable }\end{array}$ & & & & \\
\hline
\end{tabular}

The diameter of circle represents the relative position of an opportunity w.r.t. the market attractiveness and competitive position of it (which is gathered from GE Grid).

\subsection{CONCLUSION}

It is intended to find the factors that would affect and change the outlook mostly in the current status and anticipated future, based on the results obtained from environmental analysis. Using the trends to be revealed by the environmental analysis, it is possible to anticipate how the field of business in which we operate or plan to enter will evolve in the future. The status is reviewed according to the assumptions and the results to be obtained are evaluated. It is important that this step is continuously repeated taking into consideration evolving conditions and innovations.

Accordingly, assumptions are grouped under various scenarios, their potential impacts on the industry are identified, and the potential status in the industry is defined. Additionally, by taking into consideration the characteristics of the business that offer competitive advantages, the potential opportunities for the business in the industry are identified.

In conclusion, this paper is introduced to help a business to define its business opportunities by developing scenarios for the future of its existing industry and matching these positive scenarios with the competitive position of the business. Thus, the intention here is to provide strategic planners an easily understandable and applicable comprehensive procedure by using newly developed practical techniques. 


\section{REFERENCES}

Aaker, D. A., Kumar, V., Day, G. S., (2000). Marketing research, John Wiley \& Sons, New Jersey. Ansoff, H. I., (1970). Corporate strategy, Penguin, London.

Butuner, H., (2016). Case studies in strategic planning, CRC Press, Boca Raton.

Butuner, H., (2015). Systematic strategic planning: A comprehensive framework for implementation, control and evaluation, CRC Press, Boca Raton.

Fligor, M., (1990). Brainstorming: The book of topics, Creative Learning Press, Storrs.

Hitt, M. A., Ireland, R. D., Hoskisson, R. E., (2005). Strategic management: Competitiveness and globalization, Thomson South-Western, Mason.

Montgomery, C. A., Porter, M. E., (1991). Strategy: Seeking and securing competitive advantage, Harvard Business School Press, Watertown.

Porter, M. E., (1998). Competitive strategy: Techniques for analyzing industries and competitors, The Free Press, Florence.

Rasiel, E. M., (1999). The McKinsey way, McGraw-Hill Trade, Columbus.

Wheelen, T. L., Hunger, J. D., (2001). Strategic management and business policy, Prentice Hall, New Jersey.

Wickham, P. A., (2004). Strategic entrepreneurship, Pearson Education Limited, London. 